\title{
Moisture Sorption and Thermal Characteristics of Polyaramide Blend Fabrics
}

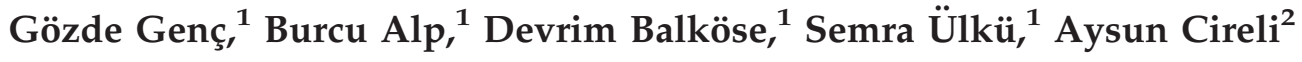 \\ ${ }^{1}$ Department of Chemical Engineering, Izmir Institute of Technology, Gülbahçe Köyü Urla İzmir, Turkey \\ ${ }^{2}$ Department of Textile Engineering, Dokuz Eylül University, Bornova Izmir, Turkey
}

Received 30 November 2005; accepted 17 January 2006

DOI 10.1002/app.24184

Published online 28 June 2006 in Wiley InterScience (www.interscience.wiley.com).

\begin{abstract}
Four types of fabrics woven from various polyaramid fibers of Nomex and Kevlar blends were characterized by morphology, XRD, elemental analysis, thermal analysis, and moisture adsorption isotherms. The blends consisted of Polybenzimidazole/Kevlar blend (40\% PBI and $60 \%$ Kevlar $^{\circledR}$ ), Nomex Delta A (blend of $60 \%$ Kevlar and $40 \%$ Nomex ${ }^{\circledR}$ ), Nomex Delta T (blend of 75\% Nomex, $23 \%$ Kevlar, and 2\% P140 antistatic fiber), and Nomex III (fabric with a $95 / 5$ blend of Nomex and Kevlar) containing $1 \%$ steel fiber. TGA and DTG curves have been compared to evaluate thermal behavior of the PBI, Kevlar, and Nomex blends and the resuls were correlated with the moisture sorption data. The data were also compared with fiber morphologies provided by SEM and crystallinities derived from XRD diffrac-
\end{abstract}

tograms. Moisture adsorption isotherms were correlated with a number of empirical models, including Nernst, Freundlich, Handersen, Iglesias-Chirife, and with the models having a theoretical background such as Langmuir, BET, $\mathrm{GAB}$, and Hüttig. The linear regression models were statistically analyzed to obtain the best fitting model that explains the sorption profiles of the samples and theoretical monolayer moisture capacities of Nomex and Kevlar blends were calculated by using Hüttig isotherms. (C) 2006 Wiley Periodicals, Inc. J Appl Polym Sci 102: 29-38, 2006

Key words: polyaromatic; blend; adsorption; isotherm; crystallinity

\section{INTRODUCTION}

Poly(para-phenylene terephthalamide) and poly(metaphenylene isophthalamide) with the trade names Kevlar and Nomex are polyaramid type polymers produced by DuPont Co. Polyaramid polymers are widely used in composite materials because of their highly specific tensile strength, modulus, chemical, and thermal resistance. They generally serve as special polymers with extraordinary thermal properties for insulation materials and fire resistant clothing. Chemical structure of the poly(para-phenylene terephtalamide) or Kevlar, poly(meta-phenylene isophthalamide) or Nomex, and polybenzimidazol (PBI), which is usually used to blend with Kevlar, are shown in Figure 1.

Wetting characteristics and moisture sorption behaviors of poly( $p$-phenylene terephthalamide) fiber and adhesion to epoxy resin were investigated by Hsieh et al. in their early studies. ${ }^{1,2}$ The subject is still challenging in the need of thermally stable composite materials but brings some problems related to compatibility and the role of permeability in the composite materials. This applies in particular to the most com-

\section{Correspondence to: G. Genç (gozdegenc@iyte.edu.tr).}

Journal of Applied Polymer Science, Vol. 102, 29-38 (2006) (C) 2006 Wiley Periodicals, Inc. mon phenomenon of moisture penetration in composites, which has become a principal limitation for industrial applications of the products of interest. Hence, the interphase plays a key role in moisture absorption behavior and affects strongly the composite response in moisture environment. The use of aramid fibers as reinforcement for organic matrices has added a new dimension to the theme of moisture diffusion into composite materials because of the ability of these fibers to absorb limited amount of water. This kind of contribution to the total diffusion behavior of the composite might be because of hydrophilic functional groups of Kevlar fibers. ${ }^{3,4}$ On the other hand, after a certain level of moisture content, glass transition temperature of thermally cured Kevlar-epoxy composites depressed and mechanical properties were affected. ${ }^{5}$ Hence the moisture sorption behavior of polyaramid fibers gain importance to correlate with mechanical properties as well as being a measure of compatibility with the matrix in composite materials.

Keinath et al. reported the Kevlar and PBI fibers' moisture sorption dependency on their chemical and physical structure besides the relative humidity. ${ }^{6}$ It has been claimed that the effect of environment on materials need to be known in the first place. Moisture sorption and desorption behavior of Kevlar were determined on adsorption controlled diffusion assumptions by small and wide angle X-Ray scattering tech- 
<smiles>CCCC(=O)c1ccc(C(=O)Nc2ccc(NC(C)C)cc2)cc1</smiles>

(a)<smiles>CCC1CCCC1=O</smiles><smiles>Cc1ccc2[nH]c(C)nc2c1</smiles>

Figure 1 Chemical structures of (a) Kevlar, (b) Nomex, and (c) PBI.

niques and gravimetric methods previously. ${ }^{7-9}$ Effect of moisture sorption on structural and mechanical properties was another issue. ${ }^{10}$ Recent studies show that moisture environment have little influence on tensile strength of polyaramide fibers, while highly humid environment significantly decreases fatigue resistance of the material. ${ }^{11,12}$ It was also reported that hygric strain of single Kevlar fiber is negative and the difference is significant. ${ }^{13}$ It has been thought that predictability of moisture sorption behavior is quite important for the materials of interest both for wettability and adhesion properties of versatile composite materials with improved mechanical properties and bearing against humidity as well as thermal stability and resistance to chemical ingredients of the environments.

Surface characteristics and coating capabilities of woven Kevlar fibers investigated by Rebouillat and coworkers was another dimension of moisture sorption phenomena. ${ }^{14,15}$ Polyaramid fibers have relatively high surface energy compared to other common rein- forcing materials. Referring to this property, chemically and thermally resistant mist filters made from polyaramid fibers were proposed to retain less water than conventional glass and polyester materials. ${ }^{16}$ Therefore, the understanding of water uptake mechanisms in terms of diffusion, condensation, and adsorption behavior of the materials is of prime consideration for an appropriate optimization in the selection of the blend components and reinforcing materials.

In this study, four types of woven polyaramid fibers consisting of $60 \%$ Kevlar- $40 \%$ PBI blend, Nomex Delta A (60\% Kevlar-40\% Nomex), Nomex Delta T (23\% Kevlar-75\% Nomex, the remainder being 2\% P140 antistatic fiber), and Nomex III (5\% Kevlar-95\% Nomex containing 1\% steel fiber) were investigated to observe moisture sorption behavior with correlation to physical structure, X-Ray diffraction (XRD) crystallinity, and thermal properties.

\section{EXPERIMENTAL}

Samples of polybenzimidazol (PBI), Nomex, and Kevlar blend fabrics with the compositions and the basic physical characteristics documented in Table I were provided by DuPont Co. as fluorocarbon treated.

Morphologies were investigated by visual observations from physical features of the woven fabrics and SEM micrographs.

XRD analysis were performed in Philips X'Pert Pro (Cu $\alpha$ 1.54) Diffractor and the elemental analysis were achieved by Energy Dissipative X-Ray (EDX) analysis with a Philips XL 30S FEG Scanning Electron Microscope.

Thermal gravimetric analysis yielding the TGA and DTG curves of the samples were achieved by Shimadzu TGA-51/51H Thermal Gravimetric Analyzer by heating under $\mathrm{N}_{2}$ atmosphere up to $1000^{\circ} \mathrm{C}$.

The fabric samples of $0.5-1.0 \mathrm{~g}$ were dried at $100^{\circ} \mathrm{C}$ for $2 \mathrm{~h}$ at vacuum oven to have dry weight prior to moisture analysis. Moisture adsorption capacities were experimentally determined in an Environmental Chamber (Angelantoni) by weighing the samples by a balance placed within the chamber until they reach equilibrium within the set humidity conditions.

TABLE I

Composition and Physical Properties of Samples

\begin{tabular}{lcccccc}
\hline \multicolumn{1}{c}{ Trade name } & $\begin{array}{c}\text { Nomex } \\
(\%)\end{array}$ & $\begin{array}{c}\text { Kevlar } \\
(\%)\end{array}$ & $\begin{array}{c}\text { PBI } \\
(\%)\end{array}$ & $\begin{array}{c}\text { Density } \\
\left(\mathrm{g} / \mathrm{m}^{2}\right)\end{array}$ & $\begin{array}{c}\text { Fiber diameter } \\
(\mu \mathrm{m})\end{array}$ & $\begin{array}{c}\text { Fabric weave } \\
\text { type }\end{array}$ \\
\hline Nomex Delta A & 40 & 60 & - & 230 & 13 & Plain weave \\
Nomex Delta T & 75 & 23 & - & 190 & 18 & Twill \\
Nomex III & 95 & 5 & - & 260 & 20 & Twill \\
Kevlar/PBI & - & 60 & 40 & 200 & 20 & Plain weave \\
\hline
\end{tabular}




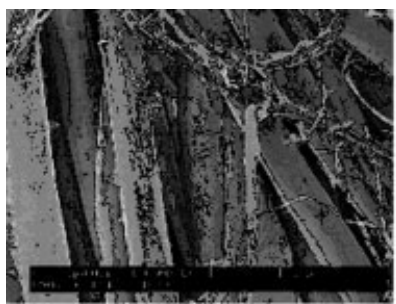

(a)

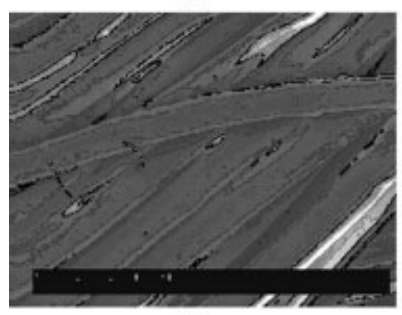

(c)

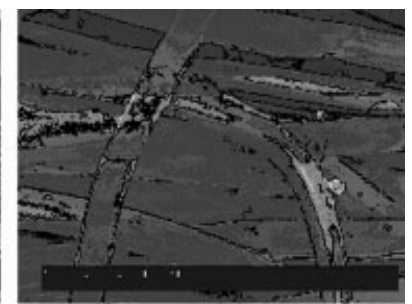

(b)

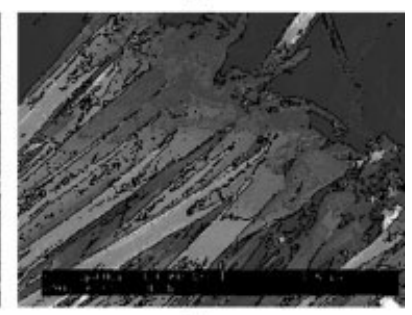

(d)
Figure 2 SEM micrographs of blend fibers at the magnifications given as (a) Nomex Delta A at $\times 1060$, (b) Nomex Delta $\mathrm{T}$ at $\times 700$, (c) Nomex III at $\times 800$, and (d) PBI Kevlar blend at $\times 500$.

\section{RESULTS AND DISCUSSION}

\section{Morphology}

Although kinetic models and diffusion phenomena of the polyaramid fibers were assumed for further investigations of moisture sorption mechanism, an early study claims the dependence of moisture sorption polyaramide materials depended mainly on physical packaging as well as chemical structure. ${ }^{6}$ The physical properties of the material are obviously vital for adsorption both in micro and macro scales even if it is chemisorption or physisorption. Therefore, the effect of morphology, including dimensions and orientations of the fibers, investigated in this study were determined from the SEM micrographs given in Figure 2. Average fiber diameters were estimated as 13, 18,17 , and $20 \mu \mathrm{m}$ for the samples of Nomex Delta A, Nomex Delta T, Nomex III, and PBI and Kevlar blends, respectively.

Moisture sorption was previously assumed to occur on microvoids to form water clusters and existence of microvoids on several type Kevlar-polyaramide fiber surface were discussed., ${ }^{71}$ No microvoids were detected on the peripheries of our fibers by SEM micro-

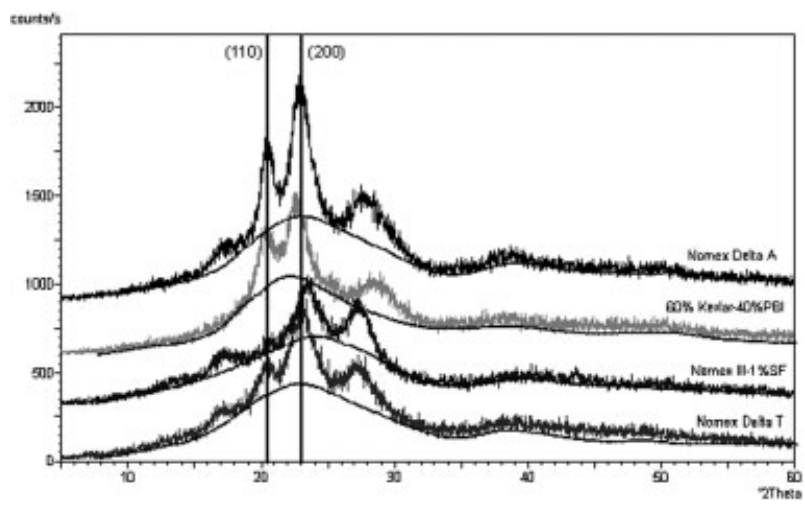

Figure 3 XRD analysis of polyaramide blends.

graphs, but from visual observations it was stated that Nomex Delta A and Nomex Delta T blends had higher surface roughness than Nomex III and PBI and Kevlar and the fibrillous structure of Nomex Delta A was supposed to causes a significant increase in surface area.

\section{XRD}

The XRD patterns of samples are shown in Figure 3 with the amorphous regions. The vertical dashed lines show the intensity peaks from 110 and 200 planes of Kevlar with $2 \theta$ values of $21.13^{\circ}$ and $23.39^{\circ}$ respectively. Diffraction intensity from 200 plane of Kevlar coincides with the diffraction from 110 and 111 planes of Nomex, which diffract at $2 \theta$ values of $23.06^{\circ}$ and $24.45^{\circ}$. So the peak shown as 200 has an enhanced intensity by the existence of Nomex for Nomex and Kevlar blends and may shift a little according to Nomex content.

Kevlar is a more crystalline material compared to Nomex with higher order in conformation. All samples have close crystallinity percentages about 25$35 \%$, with the highest crystallinities corresponding to highest Kevlar contents.

Crystallinity values tabulated in Table II were calculated after subtraction of Compton backgrounds and taking the percentage of crystalline peak areas over the area of amorphous regions. Peak overlap was neglected. ${ }^{18-21}$

TABLE II

XRD Crystallinities $(X \%)$ and the Crystal Size of the Blends

\begin{tabular}{lcrr}
\hline \multicolumn{1}{c}{ Sample } & $2 \theta(200)$ & $2 \theta(110)$ & $X(\%)$ \\
\hline Nomex Delta A (60\% Kevlar, 40\% Nomex) & 23.11 & 20.53 & 35.5 \\
Nomex Delta T (23\% Kevlar, 75\% Nomex) & 23.45 & 20.6 & 31.1 \\
Nomex III (5\% Kevlar, 94\% Nomex) & 23.68 & 20.6 & 57.3 \\
PBI and Kevlar (60\% Kevlar, 40\% PBI) & 23.17 & 20.53 & 50.9 \\
\hline
\end{tabular}


TABLE III

Elemental Analysis of Samples by EDX

\begin{tabular}{|c|c|c|c|c|c|c|c|c|c|c|}
\hline & \multicolumn{5}{|c|}{ Surface } & \multicolumn{5}{|c|}{ X-section } \\
\hline & C (\%) & N (\%) & $\mathrm{O}(\%)$ & $\mathrm{F}(\%)$ & $\mathrm{S}(\%)$ & $\mathrm{C}(\%)$ & $\mathrm{N}(\%)$ & $\mathrm{O}(\%)$ & $\mathrm{F}(\%)$ & S (\%) \\
\hline Nomex Delta A & 62.63 & 14.99 & 15.89 & 5.34 & - & 67.7 & 17.22 & 13.66 & 1.35 & - \\
\hline Nomex Delta T & 70.39 & 12.40 & 15.55 & 1.65 & - & 76.39 & 10.65 & 12.96 & 0.00 & - \\
\hline Nomex III 1\% sf. & 73.19 & 10.08 & 13.34 & 3.39 & - & 80.19 & 11.46 & 7.68 & 0.68 & - \\
\hline PBI and Kevlar & 62.03 & 15.46 & 15.29 & 4.74 & 2.48 & 68.57 & 16.35 & 14.38 & 0.70 & - \\
\hline
\end{tabular}

Crystal sizes were calculated from Sherrer equation given as eq. (1). Crystal sizes varied in the range of 5.1-11.2 nm and are tabulated in Table II. All crystal sizes have been calculated by using the $2 \theta$ values and the intensities of diffraction from the peak so called (200) in Figure 3:

$$
t=\frac{0.9 \lambda}{B \cos \theta_{a}}
$$

where $\lambda$ is wavelength of X-rays, $B$ is the breadth of the peak at $\theta_{B}$ value at half height.

\section{Elemental analysis}

The elemental analysis determined from application of EDX on the surfaces and the cross-sections of the blend fibers. The approximate contents of $\mathrm{C}, \mathrm{N}, \mathrm{O}, \mathrm{F}$, and $\mathrm{S}$ are shown in Table III. $\mathrm{C}$ content of all fibers were higher in cross section analysis (in 67.7-80.2\%) than the surface $(62.03-73.2 \%)$. On the contrary, oxygen contents were considerably higher on the surfaces with contents of $13.3-15.9 \%$ when compared to cross sections wherein values varied between $7.7-14.4 \%$. These results indicate that surface of the fibers were oxidized during processing.

Fluoro contents appeared on the surface (in 1.6$5.3 \%)$, as expected for the samples treated by fluorocarbon. Sulfur could only be detected on the surface of PBI and Kevlar blend at a percentage of $2.5 \%$. This indicated that PBI blended Kevlar was sulfonated.

\section{Thermal analysis}

TGA and DTG analysis of polyaramid blend fabric samples were employed to compare thermal behavior of PBI, Nomex, and Kevlar blends in terms of moisture contents and degradation characteristics. Figures $4-7$ consist of the TGA and DTG curves of the samples representing the blends defined in experimental section. The comparison of DTG curves in correlation to gravimetric analysis concludes that PBI and Kevlar blend has the highest thermal stability for the thermal degradation starts at more than $550^{\circ} \mathrm{C}$, which is appreciably high when compared to conventional Nomex and Kevlar blends. The onset values and weight losses for each of the DTG peaks have been tabulated (Table IV) and the residues at the end of thermal gravimetric analysis carried under $\mathrm{N}_{2}$ were also recorded.

The first peaks were related to evaporation of water adsorbed by the samples and the following weight losses until the degradation starts correspond to evaporation of fluorocarbon compound on the surface. The fastest water desorption occurs in the temperature

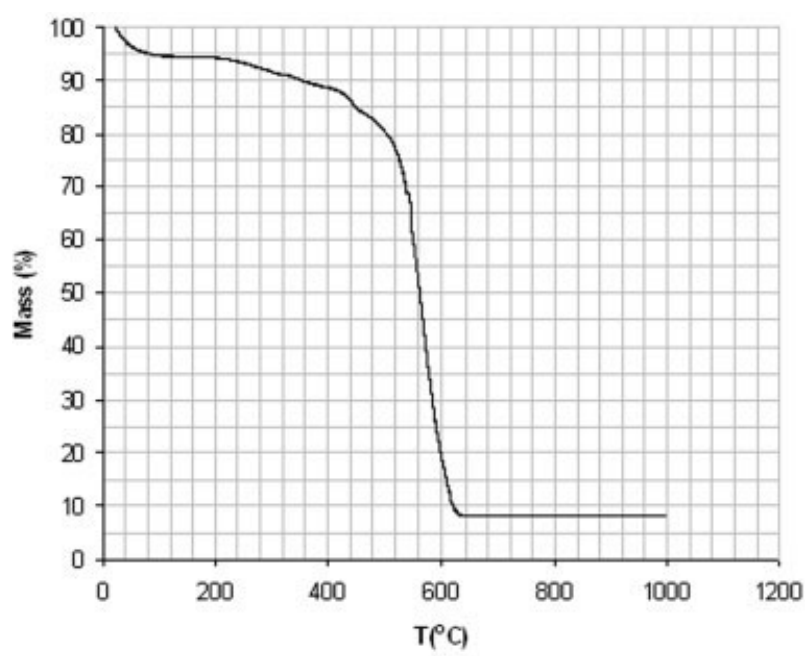

(a)

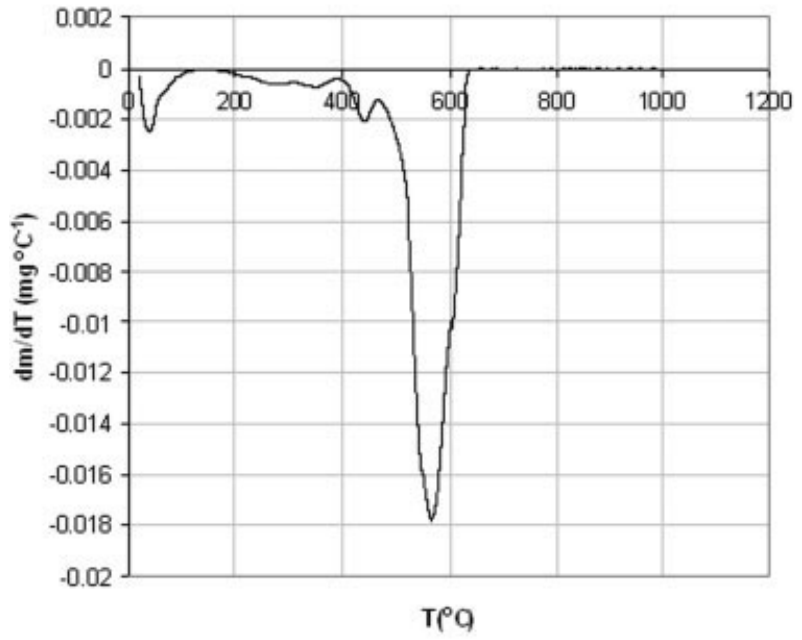

(b)

Figure 4 (a)TGA and (b)DTG of Nomex Delta A. 


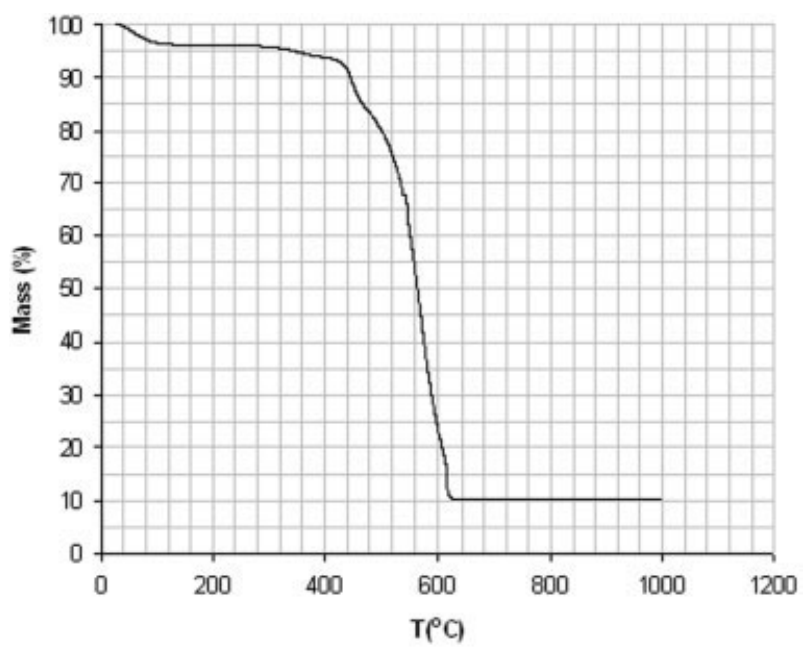

(a)

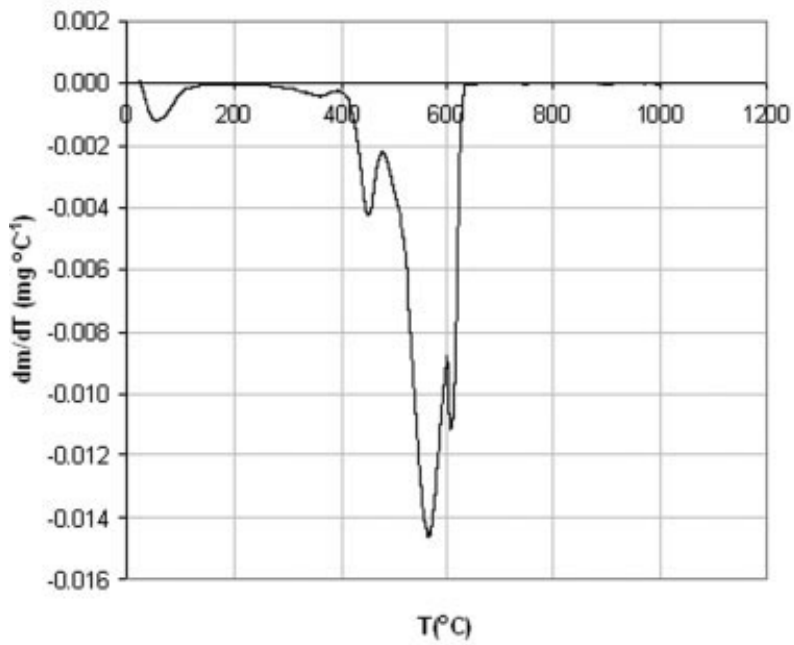

(b)

Figure 5 (a)TGA and (b)DTG of Nomex Delta T.

range of $44-67^{\circ} \mathrm{C}$ corresponding to $3.9-5.7 \%$ mass loss as seen in Table IV. The finishing material had been applied to fabric surfaces for limiting moisture sorption. The elemental analysis given in Table III confirmed with the thermal analysis that content of the finishing material is higher for the two samples of Nomex Delta A and PBI and Kevlar, both of which were $60 \%$ Kevlar blends.

Degradation onset of all samples were above $395^{\circ} \mathrm{C}$, indicating the thermal stability up to that temperature. All samples except Nomex Delta T exhibits two degradation curves before and after $480^{\circ} \mathrm{C}$ corresponding to the cleavage of hydrogen bonds, which starts at about $360^{\circ} \mathrm{C}$, and disruption of amide bonds, which can be observed at the range of $400-600^{\circ} \mathrm{C}$. For ordinary Nomex, the first peak referred to heterolytic decomposition producing aryl nitrile groups, while the peak defined at about $600^{\circ} \mathrm{C}$ may be explained by homolytic decomposition due to benzenediamines and benzonitriles of Nomex samples. In the blends,
Kevlar degrades to release hydrogen cyanide above $590^{\circ} \mathrm{C}$, which explains the second large DTG peaks in Figures $4-7 .{ }^{22-24}$

Intensities were related to variations in the content of amine groups. Hence the shifts in this peaks can be regarded as a measure of aromaticity. ${ }^{22}$ For PBI is a more aromatic compound compared to Nomex and Kevlar, and the shifts of both onset and peak values of DTA curves were expected. PBI and Kevlar blend has exhibited the highest thermal stability, which is most probably a result of a sulfonation treatment as also determined from elemental analysis. From the elemental analysis results, sulfonation degree is determined to be $28 \%$ as described elsewhere. ${ }^{25-27}$

The residues at temperatures higher than $600^{\circ} \mathrm{C}$ were $8-10 \%$. These were lower than reported $20-25 \%$ residues obtained from thermal analysis in inert atmospheres in literature. ${ }^{22-30}$

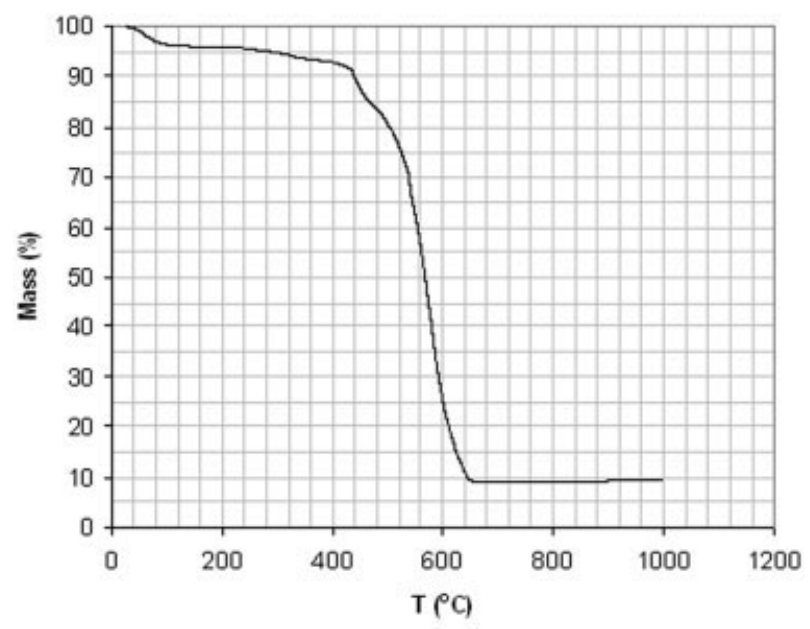

(a)

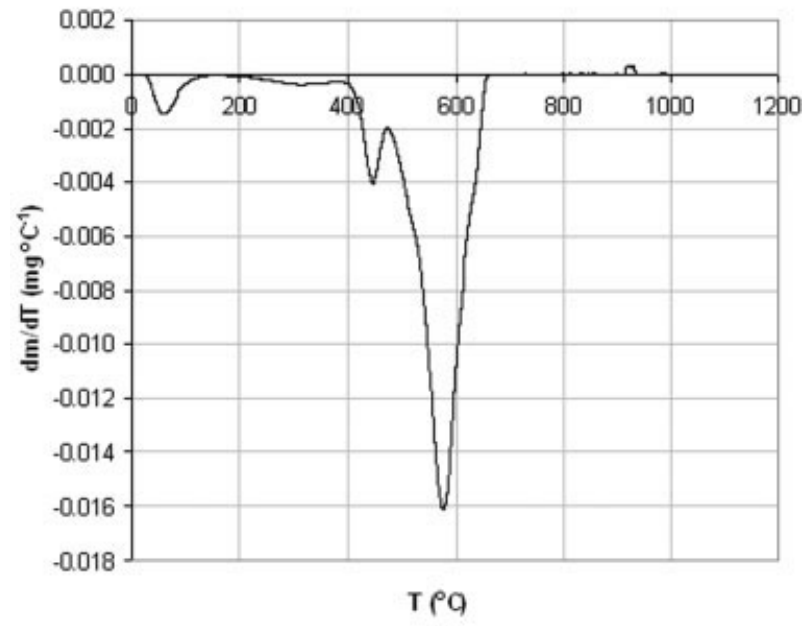

(b)

Figure 6 (a)TGA and (b)DTG of Nomex III with 1\% steel fiber. 


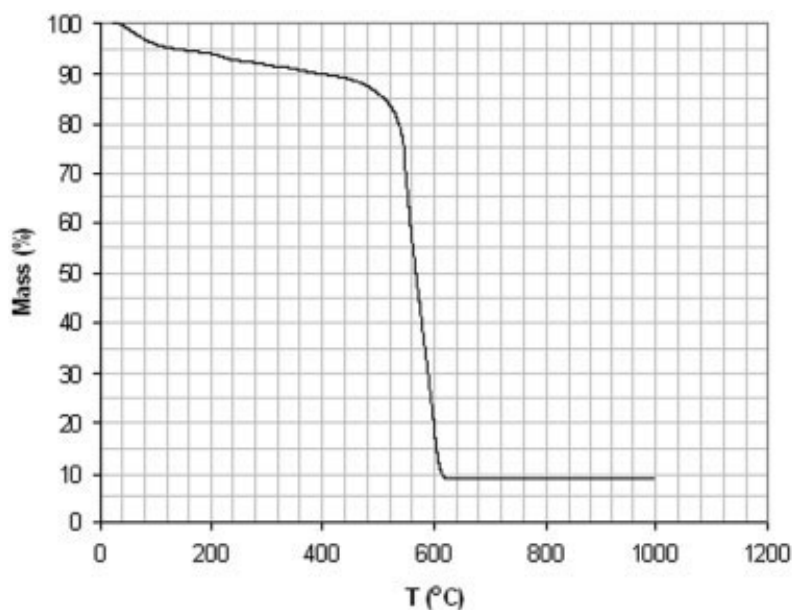

(a)

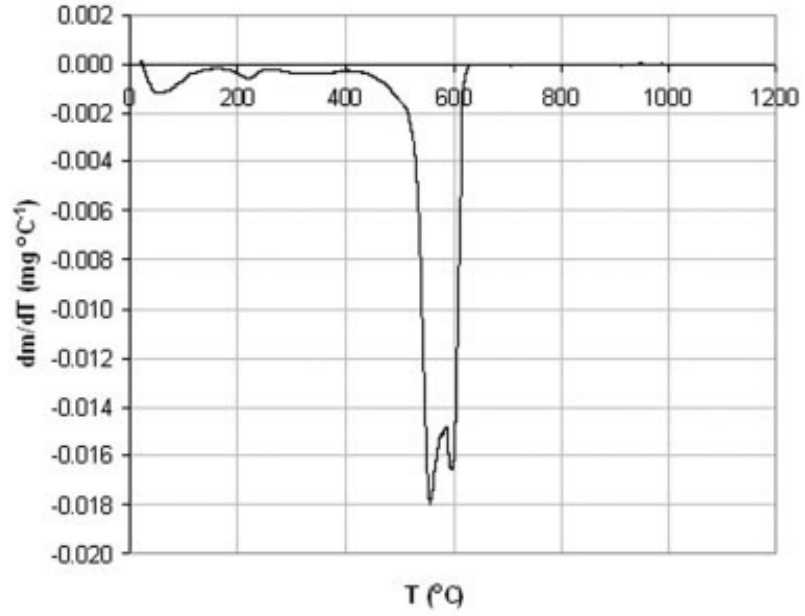

(b)

Figure 7 (a)TGA and (b)DTG of Kevlar/PBI blend.

\section{Moisture adsorption isotherms}

The sorption isotherms were compared to estimate relative moisture sorption behaviors of samples having different contents of Nomex, Kevlar, and PBI at various water activities. The first three samples with Nomex trade names (Nomex Delta A, Nomex Delta T, and Nomex III) were blends of Nomex and Kevlar;

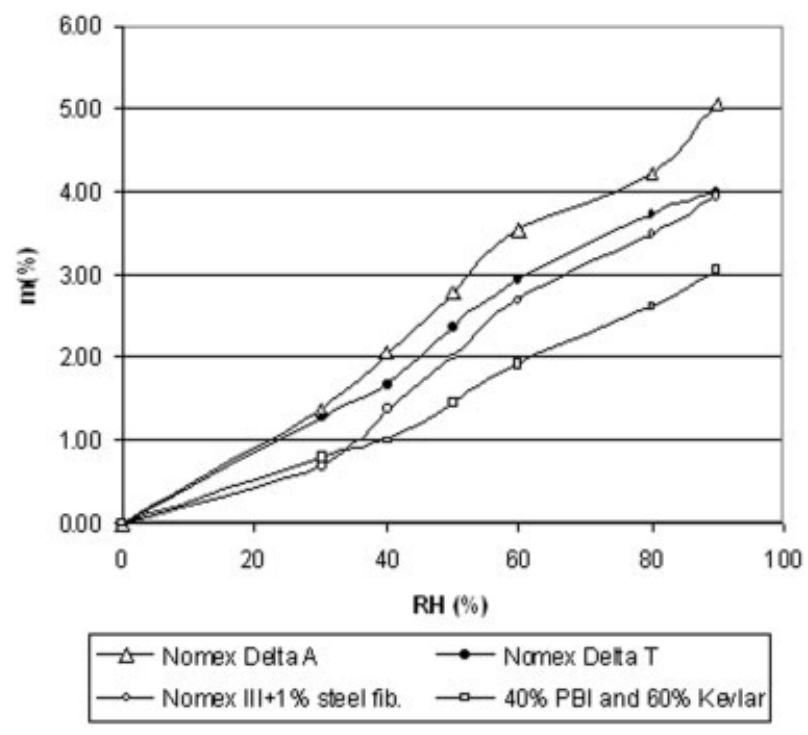

Figure 8 Moisture sorption isotherms.

Kevlar content decreasing respectively. The highest moisture sorption capacity $(5.2 \%)$ was observed for Nomex Delta A, which had the highest surface area both for the smaller fiber diameter and fibrillous structure as shown in Figure 2(a). Nomex Delta T and Nomex III exhibited very comparable moisture sorption profiles with almost identical fiber structures [Fig. 2(b,c)]. Moisture uptake of PBI used in the Kevlar blend $(3.1 \%)$ was to be smallest depending on the greatest fiber diameter of $20 \mu \mathrm{m}$ [Fig. 2(d)].

The actual moisture sorption isotherms show that Nomex Delta A has the highest moisture sorption capacity as well as it has the highest fluorocarbon content on the fiber surface. When the results of the thermal analysis were compared with moisture sorption isotherms (Fig. 8), it was observed that moisture uptake capacity of Nomex Delta A was the highest while PBI and Kevlar blend having the same 60\% Kevlar content had the lowest moisture sorption isotherms. The moisture sorption capacities were also compared with XRD crystallinities (Table II).

Evaluation of all these results show that the water adsorption behavior is obviously independent either

TABLE IV

Evaluation of TGA and DTG Analysis

\begin{tabular}{|c|c|c|c|c|c|c|c|c|c|c|c|c|}
\hline & \multicolumn{5}{|c|}{ DTG peak $\left({ }^{\circ} \mathrm{C}\right)$} & \multicolumn{5}{|c|}{$\%$ wt loss ${ }^{a}$} & \multirow{3}{*}{$\begin{array}{l}\text { Residue } \\
\text { (wt \%) }\end{array}$} & \multirow{3}{*}{$\begin{array}{l}\text { Degradation } \\
\text { onset } \mathrm{T}\left({ }^{\circ} \mathrm{C}\right)\end{array}$} \\
\hline & \multirow[b]{2}{*}{ Water } & \multirow{2}{*}{$\begin{array}{l}\text { Fluoro } \\
\text { carbon }\end{array}$} & \multicolumn{3}{|c|}{ Degredation } & \multirow[b]{2}{*}{ Water } & \multirow{2}{*}{$\begin{array}{l}\text { Fluoro } \\
\text { carbon }\end{array}$} & \multicolumn{3}{|c|}{ Degredation } & & \\
\hline & & & Peak I & Peak II & Peak III & & & Peak I & Peak II & Peak III & & \\
\hline Nomex Delta A & 44 & 362 & 450 & 572 & & 5.4 & 11.7 & 17.2 & 92.8 & & 8.2 & 407 \\
\hline Nomex Delta T & 65 & 375 & 456 & 572 & 611 & 3.7 & 6.2 & 17.0 & 77.6 & 89.7 & 10.3 & 405 \\
\hline Nomex III 1\% sf. & 67 & 321 & 452 & 582 & & 3.9 & 7.0 & 16.3 & 90.7 & & 9.3 & 395 \\
\hline PBI and Kevlar & 64 & 227 & 558 & 598 & & 4.4 & 10.2 & 67.4 & 90.2 & & 9.8 & 443 \\
\hline
\end{tabular}

\footnotetext{
${ }^{a}$ Weight losses correspond to \% mass evaporated at the offset temperature of the representative peaks signified by the local
} minima of DTG curves. 
TABLE V

Statistical Analysis of Modeled Moisture Isotherms

\begin{tabular}{|c|c|c|c|c|c|c|}
\hline Model & aw Range & Sample $^{\mathrm{a}}$ & Regression formula & $\mathrm{R}^{2}$ & SE & MSD \\
\hline \multicolumn{7}{|l|}{ Nernst } \\
\hline \multirow{4}{*}{$m=A+B(\mathrm{aw})$} & $0.3-0.9$ & I & $y=5.4872 x$ & 0.9893 & 0.171 & 0.059 \\
\hline & & II & $Y=4.5551 x$ & 0.9924 & 0.118 & 0.047 \\
\hline & & III & $y=4.1566 x$ & 0.9583 & 0.047 & 0.147 \\
\hline & & IV & $y=3.1589 x$ & 0.9773 & 0.152 & 0.100 \\
\hline \multicolumn{7}{|l|}{ Freundlich } \\
\hline \multirow[t]{4}{*}{$\ln (m)=\ln C+n \ln m$} & $0.3-0.9$ & I & $y=1.1455 x+1.7614$ & 0.9829 & 0.055 & 0.060 \\
\hline & & II & $y=1.0713 x+1.5461$ & 0.9867 & 0.045 & 0.049 \\
\hline & & III & $y=1.5300 x+1.6260$ & 0.9611 & 0.112 & 0.048 \\
\hline & & IV & $y=1.2661 x+1.2431$ & 0.9908 & 0.044 & 0.149 \\
\hline \multicolumn{7}{|l|}{ Henderson } \\
\hline \multirow[t]{4}{*}{$\ln (-\ln (1-\mathrm{aw})=\ln C+n \ln m$} & $0.3-0.9$ & I & $y=1.0104 x-0.8519$ & 0.9083 & 0.422 & -0.949 \\
\hline & & II & $y=1.3931 x-1.6342$ & 0.9369 & 0.282 & 0.148 \\
\hline & & III & $y=1.4986 x-1.4918$ & 0.9448 & 0.434 & -0.181 \\
\hline & & IV & $y=1.287 x-0.7609$ & 0.9691 & 0.106 & -0.298 \\
\hline \multicolumn{7}{|l|}{ Iglesias-Chirife } \\
\hline \multirow{4}{*}{$\ln (m)\left(m^{2}+m_{0.5}\right)^{1 / 2}=A(\mathrm{aw})+B$} & $0.3-0.9$ & I & $y=13.402 x-3.475$ & 0.9847 & 0.420 & 0.058 \\
\hline & & II & $y=10.008 x+2.7045$ & 0.9939 & 0.315 & 0.118 \\
\hline & & III & $y=10.515 x-3.5835$ & 0.9861 & 0.353 & 0.040 \\
\hline & & IV & $y=6.9112 x-2.6178$ & 0.9781 & 0.266 & 0.044 \\
\hline \multicolumn{7}{|l|}{ Chung-Pfost } \\
\hline \multirow[t]{4}{*}{$\ln (-\ln (\mathrm{aw}))=\ln A-B(m)$} & $0.3-0.9$ & I & $y=-0.6440 x+1.2872$ & 0.9337 & 0.202 & -0.073 \\
\hline & & II & $y=-0.8011 x+1.3662$ & 0.9185 & 0.224 & -0.254 \\
\hline & & III & $y=-1.709 x+0.8975$ & 0.9257 & 0.214 & -0.021 \\
\hline & & IV & $y=-1.0121 x+1.0569$ & 0.9655 & 0.146 & -0.262 \\
\hline \multicolumn{7}{|l|}{ Huttig } \\
\hline \multirow{4}{*}{$(1+\mathrm{aw}) / m=1 / m_{0}+1 / m_{0} \mathrm{Caw}$} & $0.3-0.9$ & I & $y=0.2496 x+0.0776$ & 0.9699 & 0.032 & 0.058 \\
\hline & & II & $y=0.2563 x+0.1625$ & 0.9774 & 0.028 & 0.039 \\
\hline & & III & $y=0.6111 x-0.3185$ & 0.9164 & 0.135 & 0.164 \\
\hline & & IV & $y=0.4864 x+0.0800$ & 0.9801 & 0.050 & 0.054 \\
\hline
\end{tabular}

$m$ is moisture capacity, aw is water activity, $m_{0}$ is theoretical monolayer capacity, and $\mathrm{A}, \mathrm{B}, \mathrm{C}$ are equation constants.

${ }^{a}$ I, Nomex Delta A (blend of $60 \%$ KEVLAR $^{\circledR}$ and $40 \%$ NOMEX ${ }^{\circledR}$ ); II, Nomex Delta T (blend of $75 \%$ NOMEX ${ }^{\circledR}, 23 \%$ KEVLAR $^{\circledR}$ and $2 \%$ static fiber); III, Nomex III (fabric with a 95/5 blend of NOMEX ${ }^{\circledR}$ and KEVLAR ${ }^{\circledR}$ ) containing $1 \%$ steel fiber; IV, 60\% KEVLAR ${ }^{\circledR}$ and 40\% PBI (polybenzimidazol).

of crystal size or crystallinity. It was previously reported that water molecules do not penetrate into polyaramid unit cells, but accumulate within clusters. ${ }^{31}$ As the surface treatment, which might have been responsible for the chemically bound water on the surfaces, was also ineffective, variation in moisture sorption capacities were simply explained by dependency on physical surface properties.

These results show that sorption behavior of polyaramide blends mainly depend on surface area of unit mass, which reminds condensation on the surface and monolayer adsorption in the first place.

\section{Statistical analysis of the theoretical models}

Experimental moisture uptake values were fitted to Nernst, Langmuir, Freundlich, Halsey, Henderson, Harkins-Jura, Iglesias-Chirife, Smith, Kuhn, Oswin, Chung-Pfost, BET, GAB, and Hüttig models graphically to compare regression constants and observe the consistency of experimental data with theoretical model. $^{32}$
The theoretical isotherms that did not give a linear fit or yielded regression constants $\left(R^{2}\right)$ lower than 0.90 were eliminated. The rest of the models were analyzed statistically in terms of standard errors (SE) and mean standard deviations (MSD) to determine the best theoretical approach. ${ }^{33}$

The models selected for statistical analysis are shown in Table V with $R^{2}, \mathrm{SE}$, and MSD, which were the measures of acceptability of the model. MSD values under 0.05 have been assumed as a perfect fit of experimental data to the theoretical model.

Although the previous discussions pointed a monolayer sorption behavior, Langmuir model failed for the experimental sorption isotherms of the samples. The regression constants $\left(R^{2}\right)$ were $0.37,0.18,0.58$, and 0.80 , respectively, for the samples of Nomex Delta A, Nomex Delta T, Nomex III, and PBI and Kevlar blends. That means a linear fit could not be provided by theoretical Langmuir isotherm to the experimental data. BET and GAB models failed too with regression constants lower than 0.80 , the only exception being 

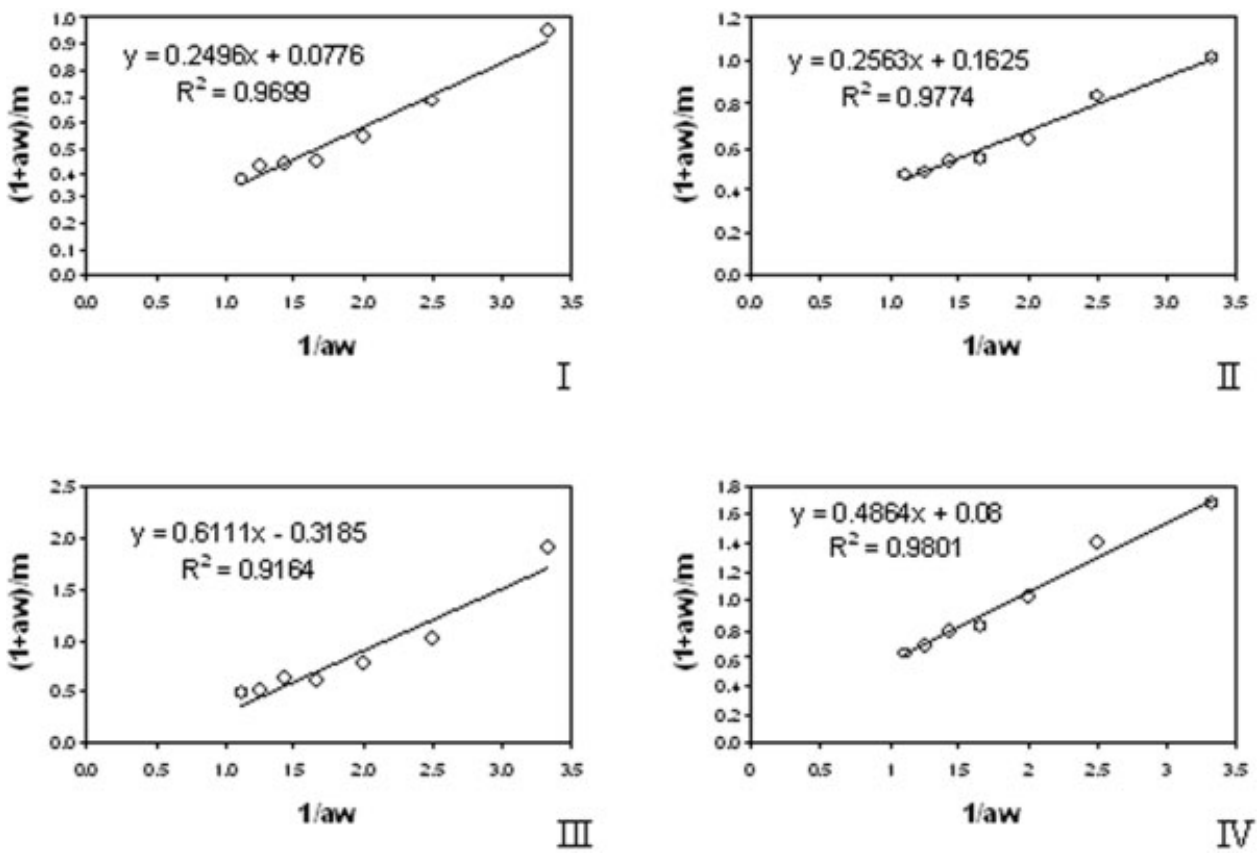

Figure 9 Moisture adsorption data fitted according to Nernst model.

Nomex III sample, which yielded a $R^{2}$ of 0.87 , even that was not an acceptable value.

Nernst model was considered for its simplicity and showing the direct correlation of adsorbed moisture amount with relative humidity of the environment (Fig. 9). The model yielded a perfect fit with Samples I and II, which consisted of Nomex Delta blends. On the other hand, Iglesias-Chrife (Fig. 10) yielded the highest regression constants with quite acceptable standard deviation values. It may provide a good predictability for moisture sorption behavior of polyaramid blend products.

Monolayer capacities $\left(m_{0}\right)$ and $C$ constants have been derived from Hüttig model by using eq. (2) - in which aw, $m, m_{0}$, and $C$ represent water activity, moisture capacity $(\%)$, theoretical monolayer capacity (\%), and the constant related to heat of adsorption, respectively-whose graphical illustration is in Figure 11. The model was derived from BET on the assumption of multilayer adsorption, which occurs on layers in-
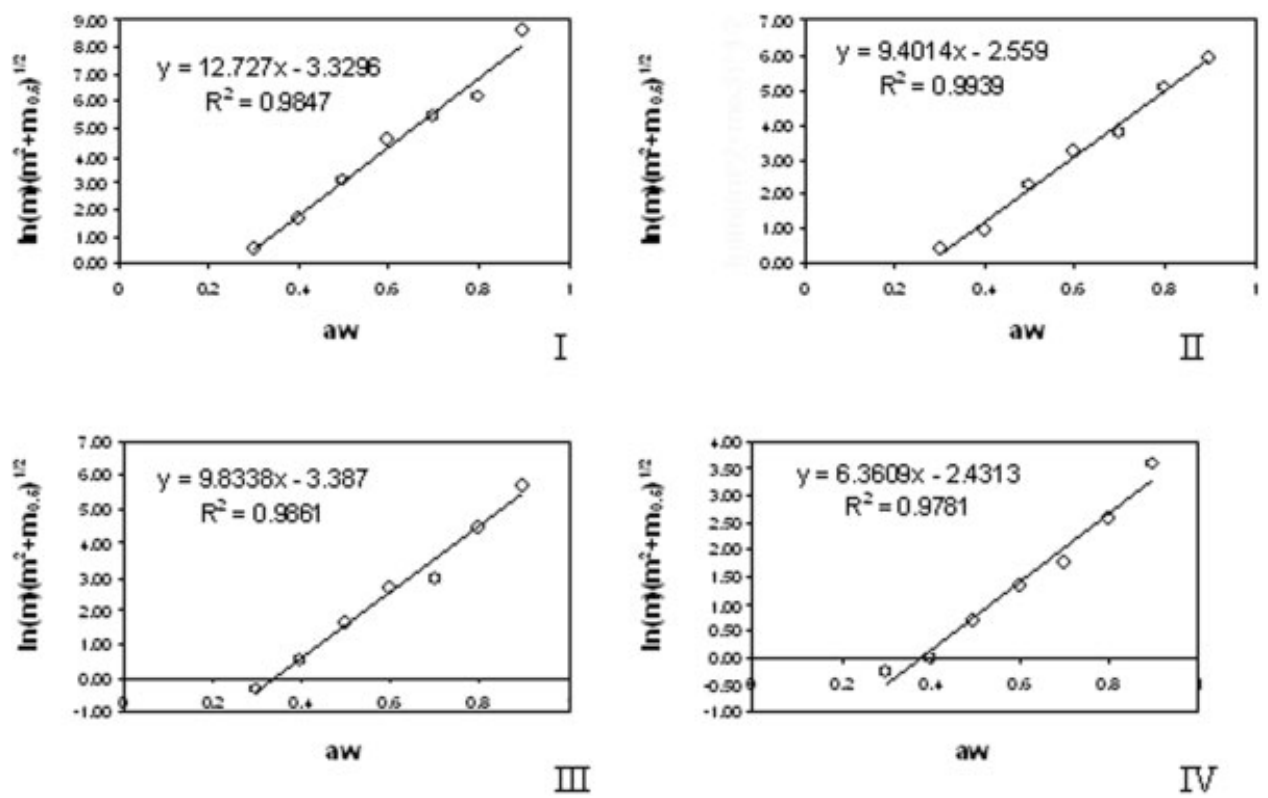

Figure 10 Moisture adsorption data fitted according to Iglesias-Chirife model. 

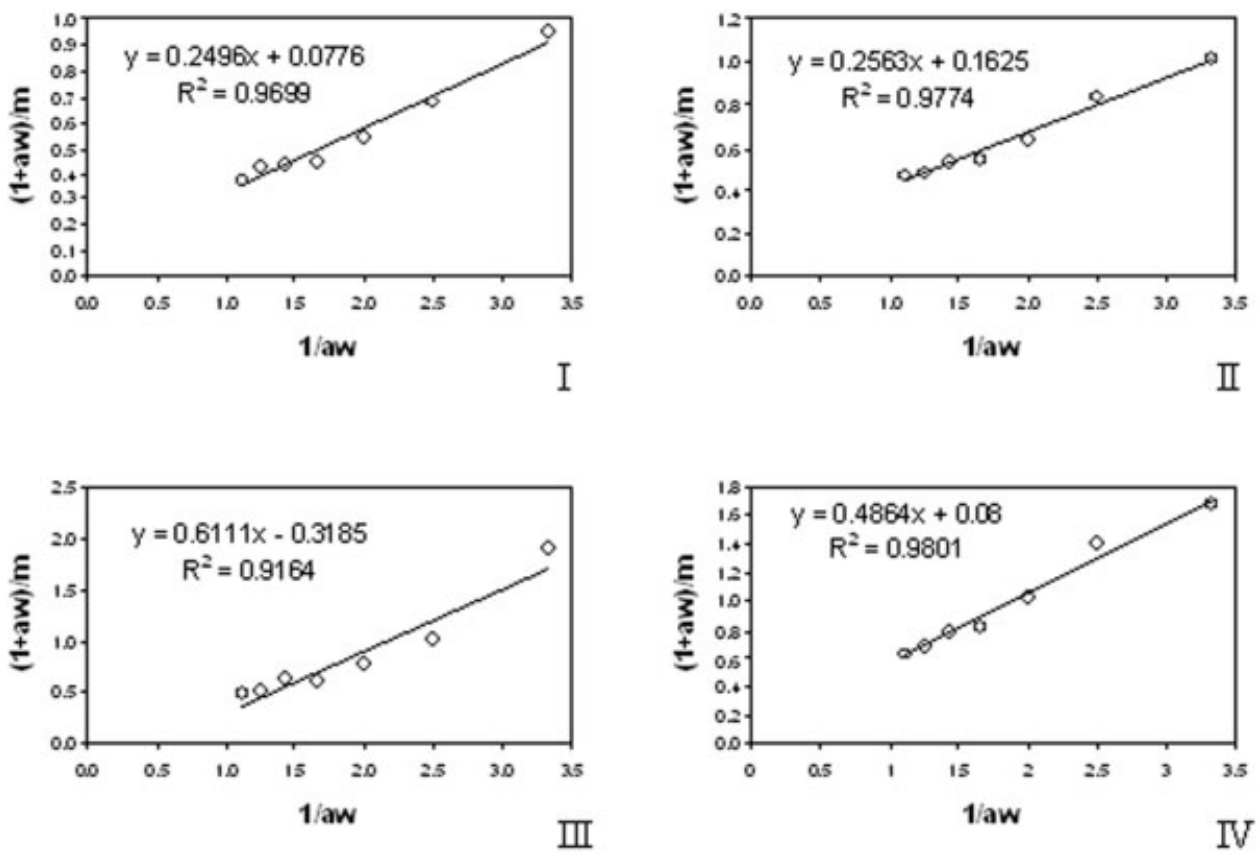

Figure 11 Moisture adsorption data fitted according to Hüttig model.

dependently of the upper layers. ${ }^{34}$ The theoretical values of monolayer capacity and equation constant derived from the model were obtained from the slope and intercept values. Those constants could be determined for Nomex Delta A and Nomex Delta T and PBI and Kevlar blend formulations because the model statistically approved for those.

$$
\frac{(1+\mathrm{aw})}{m}=\frac{1}{m_{0}}+\frac{1}{m_{0} \text { Caw }}
$$

The constants tabulated in Table VI verified that as Kevlar content increased, monolayer capacity tended to increase. PBI and Kevlar blend and Nomex Delta A both having the same Kevlar percentage $(60 \%)$ have almost the same monolayer capacities. And in contrast adsorption constant increased with increase in Nomex content.

TABLE VI

Equation Constants for Isotherms According to Hüttig Model

\begin{tabular}{lrr}
\hline & \multicolumn{2}{c}{ Huttig } \\
\cline { 2 - 3 } \multicolumn{1}{c}{ Sample } & $\begin{array}{r}m_{\mathrm{o}} \\
(\%)\end{array}$ & \multicolumn{1}{c}{$\mathrm{C}$} \\
\hline Nomex Delta A (60\% Kevlar, 40\% Nomex) & 12.89 & 0.311 \\
Nomex Delta T (23\% Kevlar, 75\% Nomex) & 6.15 & 0.634 \\
PBI and Kevlar Blend (60\% Kevlar, 40\% PBI) & 12.50 & 0.164
\end{tabular}

$m_{0}$ is monolayer capacity and $C$ is constant related to heat of adsorption.

\section{CONCLUSIONS}

Polyaramide blends of PBI, Kevlar, and Nomex were investigated in terms of thermal stability, XRD crystallinity, and moisture sorption behavior. It was found that PBI blended with Kevlar was $28 \%$ sulfonated and the product had extraordinary thermal stability, with the highest onset temperature for degradation and the lowest moisture sorption capacity. Moisture adsorption was the highest for the Nomex Delta A sample, which was a blend of $60 \%$ Kevlar and $40 \%$ Nomex. Moisture uptake increased proportional to relative humidity. All samples had low moisture sorption capacities (i.e. 3-5\%) even at $90 \%$ relative humidity. XRD crystallinity values were close for the blends and either crystallinity or crystal size did not have a significant affect on moisture sorption behavior. All samples were treated by fluorocarbon finishing material but elemental analysis did not provide a direct relationship with the surface chemistry and moisture sorption capacity. Hence, it was concluded that a molecular penetration was not the case, and moisture adsorption mechanism basically relied on physical structure of the woven fabrics and the surface area of polyaramide blend fibers per unit mass. Hüttig is a theoretical model derived from BET and it has proved the best model for polyaramide textiles made up of Nomex and Kevlar blends, yielding comparable monolayer capacities and constants for water sorption. It was designated that an increase in Kevlar content increased monolayer capacity and 
the sorption constant via adsorption energies was related with Nomex content of the blends. One may conclude that more crystalline structure of Kevlar advances monolayer sorption while Nomex content was responsible for penetration via adsorption. The model could be useful for prediction of wetting, adhesion, and dyeing ability of such blends.

\section{References}

1. Hsieh, Y. L.; Wu, M.; Andres, D. J Colloid Interface Sci 1991, 144, 127.

2. Hsieh, Y. L.; Hartzell, M. M.; Barrall, G. J Appl Polym Sci 1992, 44, 1457.

3. Varelidis, P. C.; Papakostopoulos, D. G.; Pandazis, C. I.; Papaspyrides, C. D. Compos A 2000, 31, 549.

4. Park, M.; Kim, D. S.; Kim, S. R. J Colloid Interface Sci 2003, 264, 431.

5. Akay, M.; Ah Mun, S. K.; Stanley, A. Compos Sci Techol 1997, $51,565$.

6. Keinath, S. E.; Morgan, R. J. Thermochim Acta 1990, 166, 17.

7. Saijo, K.; Arimoto, O.; Hashimoto, T.; Fukuda, M.; Kawai, H. Polymer 1994, 35, 496.

8. Fukuda, M. Polym Eng Sci 1991, 36, 558.

9. Fukuda, M.; Kawai, H. J Polym Sci Part B: Polym Phys 1997, 35, 1423.

10. Jones, C. J.; Dickson, R. F.; Adam, T.; Reiter, H.; Harris, B. Composites 1983, 14, 288.

11. Demelio, G.; Genovese, K.; Pappalettere, C. Compos B 2001, 32, 299.
12. Tanaka, K.; Komai, K. Compos Sci Technol 2004, 64, 1531.

13. Tsai, C. L.; Chiang, C. H. Compos Sci Technol 2000, 60, 2725.

14. Rebouillat, S.; Escoubes, M.; Gauthier, R.; Vigier, A. J Appl Polym Sci 1995, 58, 1305.

15. Rebouillat, S. J Mater Sci 1998, 33, 3293.

16. Letts, G. M.; Raynor, P. C.; Schumann, R. L. J Aerosol Sci 2003, 34, 1481.

17. Dobb, M. G.; Johnson, D. J.; Majeed, A.; Saville, B. P. Polymer 1979, 20, 1284.

18. Rao, Y.; Waddon, A. J.; Farris, R. J. Polymer 2001, 42, 5925.

19. Rao, Y.; Waddon, A. J.; Farris, R. J. Polymer 2001, 42, 5937.

20. Hindeleh, A. M.; Johnson, D. J. Polymer 1978, 19, 27.

21. Wang, C.-C.; Chen, C.-C. J Appl Polym Sci 2005, 96, 70.

22. Rodil, S. V.; Alonso, A. M.; Tascón, J. M. D. J Anal Appl Pyrolysis 2001, 58/59, 105.

23. Rodil, S. V.; Paredes, J. I.; Alonso, A. M.; Tascón, J. M. D. Chem Mater 2001, 13, 4297.

24. Czégény, Z. S.; Blazsó, M. J Anal Appl Pyrolysis 2001, 58/59, 95.

25. Qing, S.; Huang, W.; Yan, D. Eur Polym J 2005, 41, 1589.

26. Asensio, J. A.; Borrós, S.; Romeroa, P. G. Electrochim Acta 2004, $49,4461$.

27. Ariza, M. J.; Jones, D. J.; Rozikre, J. Desalination 2002, 147, 183.

28. Li, X. G.; Huang, M.-R. J Appl Polym Sci 1999, 71, 565.

29. Bourbigot, S.; Flambard, X.; Poutch, F. Polym Degrad Stab 2001, $74,283$.

30. Horta, J.; Coca, F.; Diez, V. Adv Polym Tech 2000, 19, 120.

31. Jain, A.; Vijayan, K. Bull Mater Sci 2000, 23, 211.

32. GreBénnikov, S. F.; Kynin, A. T. Fiber Chem 2003, 35, 360.

33. Pagano, A. M.; Mascheroni, R. H. J Food Eng 2005, 67, 441.

34. Toribio, F.; Bellat, J. P.; Nguyen, P. H.; Dupont, M. J Colloid Interface Sci 2004, 280, 315. 